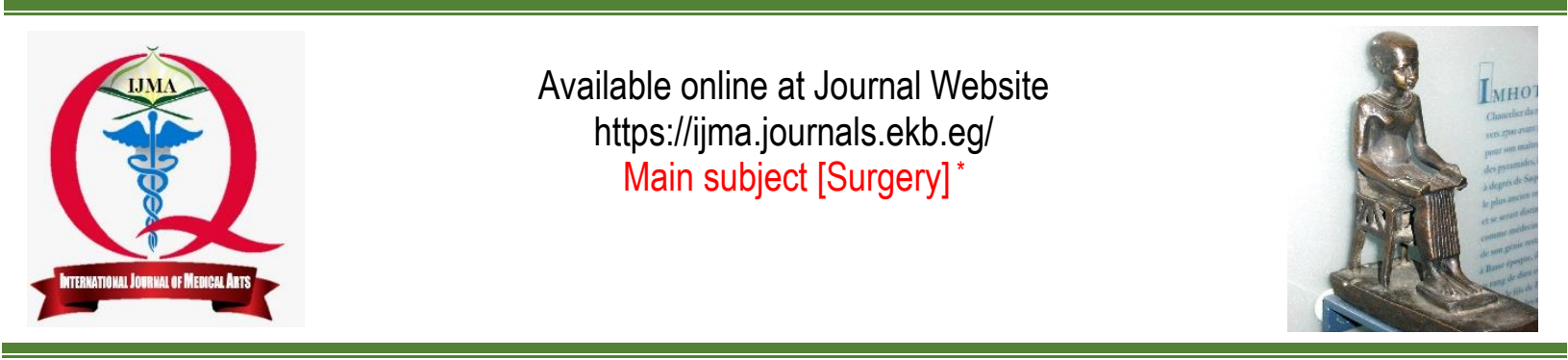

Original article

\title{
Factors Affecting Nodal Status in Breast Cancer
}

\author{
Diaa Mohammed Abo El Atta [a]; Amr Abdel-ghany Sarhan [b]; Mohammed Al Sayed Abo Mira [b]; Sami \\ Abdallah Mohammed [c]
}

Department of General Surgery, Tanta Cancer Center, Ministry of Health, Egypt $[$ a]

Department of General Surgery, Damietta Faculty of Medicine, Al-Azhar University, Egypt ${ }^{[b]}$

Department of Pathology, Damietta Faculty of Medicine, Al-Azhar University, Egypt $[c]$

Corresponding author: Diaa Mohammed Abo El Atta

Email: dia2_2017@yahoo.com

Received at: February 23, 2020; Revised at: May 10, 2020; Accepted at: May 23, 2020; Available online at: May 27, 2020

DOI: 10.21608/ijma.2020.24500.1105

\begin{abstract}
Background: Nodal status in breast cancer $[\mathrm{BC}]$ is the most prognostic factor for survival and prognosis, and affects treatment decisions. Nodal status had reciprocal relation with pre- and post-operative factors. All these reflect the crucial importance of nodal status in BC.

Aim of the work: Evaluation of pre- and post-operative factors related to nodal status in breast cancer.

Patients and Methods: The current work included 40 patients with confirmed BC, who had been scheduled for modified radical mastectomy or conservative breast surgery with axillary evacuation. All were assessed in a systematic manner preoperatively. In addition, an intraoperative and post-operative evaluation had been carried out. Postoperative histopathological examination of excised tissues had been done for all specimens. Both intra- and post-surgical complications and factors associated with positive nodal status were documented.

Results: The most significant factors associated with high positive nodal status were age [patient $\leq 45$ years was significantly associated with increased positive nodes when compared to $>45$ years [ $37.68 \pm 35.23$ vs $17.66 \pm 19.45$ respectively], obesity [30.66 \pm 27.33 vs $18.49 \pm 25.07$ nodes for obese and lean individuals respectively]., tumors greater than 2 $\mathrm{cm}$, positivity of the human-epidermal-growth-factor receptor 2 [Her2]/neu, positive lymphovasular invasion, tumors of the upper quadrant, and the type of histopathology.

Conclusion: Nodal status affected by pre- and post-surgery factors [e.g., age, obesity, tumor site, tumor size, Her2/neu, lymphovascular invasion and histopathological type of the tumor]. Thus, these factors help in planning of the treatment such as the type of surgery, endocrine therapy, radiation therapy and the adjuvant chemotherapy.
\end{abstract}

Keywords: Axillary evacuation; Breast cancer; Lymph nodes; Adjuvant therapy; Prognosis.

This is an open access article under the Creative Commons license [CC BY] [https://creativecommons.org/licenses/by/2.0/]

Please cite this article as: Abo El Atta DM, Sarhan AA, Abo Mira MA, Mohammed SA. Factors Affecting Nodal Status in Breast Cancer. IJMA 2020; 2[3]: 535-541.

* Main subject and any subcategories have been classified according to research topic. 


\section{INTRODUCTION}

Breast cancer $[\mathrm{BC}]$ ranked first among malignant diseases of the Egyptian females, and account for $32 \%$ of all female cancers. In cancer related mortality, $\mathrm{BC}$ is the first and is responsible for about $15 \%$ of worldwide deaths per year. It affects older females, with marked increase in their fifties and highest incidence registered among 70 s or older. In Egypt, there was an increase in old populations above 65 years [increased from $3.7 \%$ in 2006 to $9.3 \%$ in 2014]. Life expectancy had been also increased to reach 76 years in female and 70 years in males ${ }^{[1]}$. Nodal status is the most important prognostic factor for survival in $\mathrm{BC}$ patients ${ }^{22]}$. Before the mid-1990s, axillary dissection was the standard method of staging of locoregional metastatic node, including patients with early BC. The state of axilla was directive for both staging of $\mathrm{BC}$ and planning of its main or adjuvant therapy ${ }^{[3]}$.

Axillary lymph node clearance it is the golden standard for detecting metastases. National guidelines state that "axillary procedure should be done in invasive breast tumors. [4]

Several attempts were made to asses positive axillary node predictors which could lead to targeted use of axillary lymph node dissection. Factors relation to patient or tumor feature had been considered to play a crucial role with higher risk of axillary node involvement in $\mathrm{BC}$ [e.g., patient age, lymphovasular invasion, tumor grade, hormone receptor status, tumor size and human epidermal growth factor receptor 2 [HER-2]/neu status] [5].

The significant importance of lymph node involvement reflected by the fact that, 5 -year survival rate had been reached up to $94.4 \%$ for patients with negative node involvement and had been dropped to $58 \%$ in patients with axillary nodes involvement.

The current standard in surgical treatment is dissection of the axillary lymph node to minimize axillary recurrence. This treatment is intended to remove any cancer cells that may be residing in those lymph nodes [6]

\section{AIM OF THIS STUDY}

This research aimed to determine pre- and postsurgery factors which could affect nodal status in breast cancer.

\section{PATIENTS AND METHODS}

A prospective study of 40 patients, with operable breast cancer had been carried out. They were selected from Al-Azher University Hospital [Damietta] and all scheduled for modified radical mastectomy or conservative breast surgery with axillary evacuation. All resected tissues had been sent for histopathological examination.

Factors could be associated to nodal status were examined and documented. These factors included: tumor size, patient age, histopathological type, tumor size, lymphovascular invasion and positivity or negativity for estrogen, progesterone receptors and HER2/neu, tumor grade, obesity [body mass index] and positive family history. The only inclusion criterion in the current work was the pathological proven, operable breast cancer. On the other side, patients with male breast cancer, patients administer neoadjuvant therapy or with lymph node dissection number less than 10, were excluded from the study.

Informed consents had been obtained from all patients included in the study which were approved by the local ethics committee of our institution.

At preoperative period, all necessary laboratory investigations [e.g., imaging study [Plain X-ray, abdominal ultrasound, Echocardiography and metastatic workup] had been carried out. In addition, different intraoperative data had been documented [e.g., operative time, injury to axillary vein, thoracodorsal nerve or long thoracic nerve and amount of blood loss]. Any postoperative complications had been documented [e.g., seroma formation, wound infection and time to remove drain]. Surgical techniques had been performed as described by Chen et al. [7]

The collected data had been coded, fed to personal computer and statistically analyzed using a computer statistical package [Statistical Package for Social Sciences, version 22.0 [IBM SPSS Statistics for Windows, Armonk, NY, USA]. P value $\leq 0.05 \%$ was considered significant. Quantitative data were presented as mean and standard deviation for normally distributed data; and median for abnormally distributed data, while categorical data presented as frequency and percentages. Student [t], and Chi square tests were used for comparison between groups according to type of data. 


\section{RESULTS}

Table [1] summarizes the pre- and post-operative data which could significantly affect nodal status in the 40 patients according to percentage of positive axillary nodes. Patient age younger than or equal to 45 years was significantly associated with increased number of positive nodes when compared to ages older than 45 years $[37.68 \pm 35.23$ vs $17.66 \pm 19.45$ years respectively]. In addition, obese patients had significantly higher numbers when compared to patients with normal body mass index [BMI] [30.66 \pm 27.33 vs $18.49 \pm 25.07 \mathrm{~kg} / \mathrm{m}^{2}$ respectively]. Furthermore, upper outer quadrant was associated with high positive nodes, followed by lower outer quadrant and the least site was the retro-areolar. Increased tumor size was associated with more positive nodes. In addition, positive lymphovascular invasion and Human Epidermal Growth Factor Receptor 2 were associated with increased positive nodes. Finally, the mixed type [invasive ductal carcinoma plus Invasive lobular carcinoma] was associated with significant increased number of positive nodes. Followed by the invasive lobular carcinoma histopathological type.

On the other side, table [2] presented the pre-and post-surgery factors that insignificantly associated with positive nodal status in 40 patients. These factors include estrogen receptor, progesterone receptor, tumor grade, and family history

Table [1]: Summarizes the significant associated factors in relations to number of axillary lymph nodes.

\begin{tabular}{|c|c|c|c|c|c|c|c|}
\hline & & & \multicolumn{3}{|c|}{ Number of nodes } & & \\
\hline \multicolumn{2}{|c|}{ Significant factors } & $\mathrm{N}$ & Min. - Max. & Mean \pm SD & Median & Test & $P$ \\
\hline \multirow[t]{2}{*}{ Age } & $\leq 45$ & 12 & $3.85-100.0$ & $37.68 \pm 35.23$ & 25.0 & \multirow[t]{2}{*}{101.5} & \multirow[t]{2}{*}{$0.048^{*}$} \\
\hline & $>45$ & 28 & $0.0-63.64$ & $17.66 \pm 19.45$ & 12.02 & & \\
\hline \multirow[t]{2}{*}{ BMI $\left[\mathrm{Kg} / \mathrm{m}^{2}\right]$} & $\leq 25$ & 23 & $0.0-91.43$ & $18.49 \pm 25.07$ & 5.88 & \multirow[t]{2}{*}{123.0} & \multirow[t]{2}{*}{$0.046^{*}$} \\
\hline & $>25$ & 17 & $0.0-100.0$ & $30.66 \pm 27.33$ & 23.81 & & \\
\hline \multirow[t]{5}{*}{ Site } & UOQ & 10 & $0.0-100.0$ & $54.52 \pm 33.08$ & 60.77 & \multirow[t]{5}{*}{13.933} & \multirow[t]{5}{*}{$0.008^{*}$} \\
\hline & LOQ & 6 & $0.0-42.86$ & $25.14 \pm 14.94$ & 29.0 & & \\
\hline & $\mathrm{UIQ}$ & 9 & $0.0-33.33$ & $13.70 \pm 13.15$ & 5.0 & & \\
\hline & LIQ & 6 & $0.0-25.0$ & $14.64 \pm 8.86$ & 15.36 & & \\
\hline & Retro areolar & 9 & $0.0-15.79$ & $4.37 \pm 5.27$ & 3.85 & & \\
\hline \multirow[t]{2}{*}{ Size } & $<2$ & 6 & $0.0-15.79$ & $5.09 \pm 5.80$ & 4.42 & \multirow[t]{2}{*}{50.0} & \multirow[t]{2}{*}{$0.048^{*}$} \\
\hline & $2->5$ & 34 & $0.0-100.0$ & $26.94 \pm 27.32$ & 20.09 & & \\
\hline \multirow[t]{2}{*}{ Her2/neu } & Negative & 34 & $0.0-100.0$ & $17.69 \pm 20.95$ & 12.02 & \multirow[t]{2}{*}{35.0} & \multirow[t]{2}{*}{$0.011^{*}$} \\
\hline & Positive & 6 & $0.0-91.43$ & $57.54 \pm 30.50$ & 63.96 & & \\
\hline \multirow[t]{2}{*}{ LVI } & No & 21 & $0.0-63.64$ & $13.10 \pm 15.16$ & 6.67 & \multirow[t]{2}{*}{122.50} & \multirow[t]{2}{*}{$0.036^{*}$} \\
\hline & Yes & 19 & $0.0-100.0$ & $35.34 \pm 31.36$ & 31.25 & & \\
\hline \multirow[t]{3}{*}{ histopathological type } & IDC & 32 & $0.0-100.0$ & $18.30 \pm 24.84$ & 8.93 & \multirow[t]{3}{*}{7.349} & \multirow[t]{3}{*}{$0.025^{*}$} \\
\hline & ILC & 4 & $0.0-64.29$ & $41.07 \pm 28.56$ & 50.0 & & \\
\hline & $\begin{array}{l}\text { Mixed IDC + } \\
\text { ILC }\end{array}$ & 4 & $28.0-68.0$ & $49.19 \pm 17.50$ & 50.38 & & \\
\hline
\end{tabular}

IDC: Invasive duct carcinoma; ILC: Invasive lobular carcinoma; UOQ: Upper outer quadrant; UIQ: Upper inner quadrant; LOQ: Lower outer quadrant; LIQ: Lower inner quadrant; BMI: Body Mass Index; LVI: Lymphovascular Invasion; HER-2: Human Epidermal Growth Factor Receptor 2

Table [2]: summarizes the non-significant associated factors in relations to number of axillary lymph nodes.

\begin{tabular}{|c|c|c|c|c|c|c|c|}
\hline \multicolumn{2}{|c|}{ Insignificant factors } & $\mathrm{N}$ & Min. - Max. & Mean \pm SD & Median & MW & $P$ \\
\hline \multirow[t]{2}{*}{ Estrogen receptor } & Negative & 8 & $0.0-68.0$ & $25.64 \pm 25.91$ & 20.67 & \multirow[t]{2}{*}{118.0} & \multirow[t]{2}{*}{0.734} \\
\hline & Positive & 32 & $0.0-100.0$ & $23.17 \pm 26.94$ & 16.23 & & \\
\hline \multirow{2}{*}{ Progesterone receptor } & Negative & 6 & $0.0-68.0$ & $28.41 \pm 29.28$ & 22.29 & \multirow[t]{2}{*}{94.0} & \multirow[t]{2}{*}{0.761} \\
\hline & Positive & 34 & $0.0-100.0$ & $22.83 \pm 26.28$ & 16.23 & & \\
\hline \multirow[t]{2}{*}{ Tumors grade } & Low & 32 & $0.0-100.0$ & $24.59 \pm 27.58$ & 16.23 & \multirow[t]{2}{*}{116.50} & \multirow[t]{2}{*}{0.696} \\
\hline & High & 8 & $0.0-64.29$ & $19.95 \pm 22.41$ & 15.36 & & \\
\hline \multirow[t]{2}{*}{ Family history } & Negative & 38 & $0.0-91.43$ & $22.28 \pm 23.70$ & 16.23 & \multirow[t]{2}{*}{34.0} & \multirow[t]{2}{*}{0.803} \\
\hline & Positive & 2 & $0.0-100.0$ & $50.0 \pm 70.71$ & 50.0 & & \\
\hline
\end{tabular}




\section{DISUCSSION}

Axillary node involvement is the most significant and prognostic factor in BC, because metastatic node interferes with therapeutic decisions of systemic adjuvant therapy[8]. Factors associated with lymph node involvement- in turn- affect the treatment plan and identification of such factors of crucial importance, and many are related to patient criteria or tumor characteristics [9]. Hence the importance of the current work to explore factors significantly associated with lymph node involvement in BC.

Results revealed that, age is a protective factor for axillary lymph node metastasis, as it decreased in old age. As the breast cancers considered as hormonal-related disease, with significant hormonal decrease with advanced age, this could explain the current findings, as described in previous work [10].

Rabaglio and Castiglione study [Surveillance, Epidemiology, and End Results [SEER] program of the United States] showed that $75 \%$ of breast tumors occurred in women aged $>50$ years, only $6.5 \%$ in women aged $<40$ years, and a mere $0.6 \%$ in women below 30 years. In the age group below 35, the incidence is $1.8 \%$ and the mortality is $6.4 \%$. These epidemiological characteristics remain stable in the most published reports. An analysis using data from nine registries of the SEER showed that the number of tumor-infiltrating lymphocytes in breast cancer decreases with age [11]. These results agree with the current study. Ling and Li-Zhang ${ }^{[12], ~ C h i s t h i ~ a n d ~}$ Kuttanchettiyar[13] reported that, younger age, HER/2neu positivity and higher histological grade are associated with more risk of axillary disease. These results are supported by the current work.

Chakraborty et al. reported results of 426 patients with BC [treated during March 2010 to December 2013]. They reported that, whatever the patient age, status of estrogen and progesterone receptor did not associated with the node metastasis ${ }^{[14]}$. These results partially agree with the current work regarding estrogen and progesterone receptors, but they did not agree regarding patient age.

Obesity in the current work was significantly associated with positive axillary lymph nodes. Bhardwaj and colleagues agree with our study and reported that, obesity is a risk factor for estrogen receptor-positive breast cancer after menopause.
The effects of estrogens proliferation help the growth of body is evidence of the important role in tumor genesis. Importantly, obesity not causes breast cancer, but it associated with other factors such as loco-regional recurrence, metastasis of axillary nodes and cancer-associated death [15]

Also, Picon-Ruiz and colleagues carried a study between 2011 and 2014, in the United States, and reported that, obesity had been associated with premature menopause and premature menopause increased the risk of breast cancer ${ }^{[16]}$. Guldberg and colleagues also revealed that, premenopausal breast cancer women who are overweight and have poorer physical function have poorer prognosis [17].

On the other side, Keskin et al. study showed no significant relation between body mass index and metastatic node in $\mathrm{BC}[18]$, which disagree with the current work. This could be explained by different inclusion criteria.

Tumor site, mainly upper and lower outer quadrants were associated with significant increase of metastatic nodes. These results agree with Siotos and colleagues' study. They included 5295 BC patients from 2003 to 2015,5295 . Tumors originated from the upper outer quadrant were associated with increased higher odds risk of nodal metastasis. In addition, tumors from the lower-outer quadrant were associated with lower risk of death [19]. Furthermore, Gou and colleagues reported that, the worse prognosis occur at upper-outer quadrant [20].

On the other side, Desai and colleagues showed that, tumor located in the nipple, central breast, and axillary tail have the highest risk of metastasis of axillary nodes [21]. Tumors more than $2 \mathrm{~cm}$ in the current study had been associated with positive axillary lymph node than tumors less than $2 \mathrm{~cm}$ in size. Ojha and colleagues study reported that, the length of tumor to skin playing role at axillary lymph nodal metastasis in invasive breast cancers. Closer tumor had more incidence of axillary nodal metastasis [22]. This explains the current findings. Also, Kurnaz and colleagues study showed that, axillary lymph node deposits increases with tumors more than $2 \mathrm{~cm}$ in diameter and invasive ductal carcinoma [23]. Analysis of the current study showed that, the metastatic deposit of axillary lymph node higher in estrogen and progesterone receptor negative tumors than estrogen and progesterone positive patients but the results did not reach 
statistical significance. Goodman et al. reported that, STAT1 is the main mediator of IFN-signaling in tumors growth. In addition, the immune system plays an important role in proliferation of breast cancer cells, mainly through interaction between the progesterone receptor [PR] and STAT1. The tumor proliferation stopped by this interaction which inhibits the phosphorylation of IFN-induced STAT1, and could be used as an endocrine therapy in PRpositive disease through inhibition the phosphoSTAT1 in response to IFN. Moreover, the absence of PR led to increased recruitment of STAT1, STAT2, and IRF9 [key transcription factors necessary for IFN-stimulated gene transcription] to IFN-stimulated genepromoters [24]. In addition, Sohn and colleagues reported non- statistical relation between ER, PR, HER2, and Ki-67 status in core needle biopsy specimens correlated well with their status in surgical specimens. The HER2 status was the most accurately assessed factor [25]. In regard to HER2, their results did not support by the current work.

Chakraborty and colleagues reported that, axillary node positivity related with breast tumors behaviors such as [grading, size and lymphovascular invasion of tumor] [14].

In the current work, Her2/neu expression is an important predicator for positivity of axillary lymph nodes. Tong and colleagues reported that, Her2/neu had a significant role in the regulation of cell growth, proliferation, and differentiation of tumor cells. Significantly HER-2 expression plays a crucial role in regulation the growth in breast cancer tissues. The level of expression HER-2 was significantly related to the axillary metastasis ${ }^{[26]}$.

Chisthi and Kuttanchettiyar showed that, HER2/neu positivity and higher histological grades are associated with more risk of axillary disease not the size of tumor[13]. However, BadowskaKozakiewicz et al said that, Her2/neu expression not significantly at deposit of axillary nodes [27].

Lymphovascular invasion, in the current work had been showed to be an important predicator for axillary lymph node metastasis. Öz and colleagues said that, lymphovascular invasion is a predicting factor for metastatic axillary node invasion [28]. Ilhem et al. also considered lymphovascular invasion and molecular subtypes as the strongest predictors of axillary lymph node metastasis [29]. However, Fujii and colleagues reported that, lymphovascular invasion was no regarded as a metastatic deposit of axillary lymph node [30].

In the current study, the lobular carcinoma and mixed lobular and ductal types had positive metastatic axillary nodes more than in ductal carcinoma. It has been demonstrated that loss of expression of the cell-cell adhesion molecule Ecadherin in infiltrating lobular carcinoma may decrease adhesiveness of cells and facilitate this type of infiltration [31]. This could explain the current results. Chen et al. reported included a total of 796,335 patients with infiltrating lobular carcinoma or infiltrating ductal carcinoma. Infiltrating lobular carcinoma had been reported among [10.7\%] infiltrating ductal carcinoma among [89.3\%]. The metastasis significantly increased in the infiltrating lobular carcinoma group [infiltrating lobular carcinoma vs. infiltrating ductal carcinoma, $[5.5 \%$ vs. $3.8 \%$ ] [32]. However, Williams and colleagues reported that malignant axillary deposit increase in ductal than in lobular and mixed carcinoma [33]

In this study statistical analysis reported that tumor grade 2 had positive metastatic axillary lymph node more than tumor grad 3. Chisthi et al. [13] reported that, grade 2 tumors cells tend to be slow growing which occur at invasive tumor growth cycle is longer and this increase opportunity of lymphovascular invasion. Younger age, HER2/neu positivity and higher histological grade are associated with more risk of axillary disease.

Positive family history had been considered as a predicator for positive node involvement, but in the current work, it did not reach statistical significance. Females with positive family history of $\mathrm{BC}$ are more likely to undergo screening exams, however did not report healthier behaviors more often than those without such a history. Breast cancer control programs must estimate the physical activity, weight control, healthier diet, smoking cessation and reduction of alcohol drinking [34].

Bertoni et al. suggested that, family history with breast cancer is not sufficient to change physical activity according women's behaviors, control of weight and smoking, diet, and drinking, but it increased the risk of breast cancer screening behavior[34]. However, Brewer et al. said that, a positive family history score can give greater risk discrimination on breast cancer incidence and positivity of axillary lymph node. Significant increase 
risk of cancer with greater family history score [35]. This could be explained by different inclusion criteria and different number of patients studied.

Conclusion: Survival, staging and typical treatment options for breast cancer patients are significantly related to nodal status which affected by pre- and post- surgery factors [e.g., age, obesity, tumor site, tumor size, Her2/neu, lymphovascular invasion and histopathological type of the tumor]. These certain factors help in planning of the treatment such as the type of surgery, endocrine therapy, radiation therapy and the adjuvant chemotherapy.

\section{Financial and Non-Financial Relationships and Activities of Interest}

None

\section{REFERENCES}

1. Ibrahim NY, Talima S, Makar WS. Clinico-Epidemiological Study of Elderly Breast Cancer in a Developing Country. Egypt. J Cancer Treat Res. 2019;7[1], p.23. [DOI: 10.11648/j.jctr.20190701.14]

2. Cho DH, Bae SY, You JY, Kim HK, Chang YW, Choi YJ, et al. Lymph node ratio as an alternative to $\mathrm{pN}$ staging for predicting prognosis after neoadjuvant chemotherapy in breast cancer. Kaohsiung J Med Sci. 2018; 34[6]:341-347. [DOI: 10.1016/j.kjms.2017.12. 015].

3. Sun SX, Moseley TW, Kuerer HM, Yang WT. ImagingBased Approach to Axillary Lymph Node Staging and Sentinel Lymph Node Biopsy in Patients with Breast Cancer. AJR Am J Roentgenol. 2020; 214[2]:249-258. [DOI:10.2214/AJR.19.22022]

4. Cui X, Wang N, Zhao Y, Chen S, Li S, Xu M, Chai R. Preoperative Prediction of Axillary Lymph Node Metastasis in Breast Cancer using Radiomics Features of DCE-MRI. Sci Rep. 2019;9[1]:2240. [DOI:10.1038/ s41598-019-38502-0].

5. Ojha SS, Jain RA, Nilkanthe RG, Meenai FJ, Abhishek S, Amit HK. Distance of tumor to skin as a predictive marker for axillary lymph node metastasis in cases of breast carcinoma-A retrospective study. Indian J Med Paed Oncology. 2018; 39[3]: 321-325. [DOI: 10.4103 / ijmpo. ijmpo_26_17].

6. Joo JH, Kim SS, Son BH, Ahn SD, Jung JH, Choi EK, et al. Axillary lymph node dissection does not improve post-mastectomy overall or disease-free survival among breast cancer patients with 1-3 positive nodes. Cancer research and treatment: official $\mathrm{J}$ Korean Cancer Assoc. 2019;51[3]: 1011-1021. [DOI: 10.4143/ crt.2018.438].

7. Chen D, Lai L, Duan C, Yan M, Xing M, Chen J, Zhang F. Conservative surgery plus axillary radiotherapy vs. modified radical mastectomy in patients with stage I breast cancer. Clin Breast Cancer. 2014;14 [1]: e10-3. [DOI: 10.1016/j.clbc. 2013.09.007].

8. McDonald ES, Clark AS, Tchou J, Zhang P, Freedman GM. Clinical Diagnosis and Management of Breast Cancer. J Nucl Med. 2016; 57 Suppl 1:9S-16S. [DOI:10.2967/jnumed.115.157834].

9. Verheuvel NC, Ooms HW, Tjan-Heijnen VC, Roumen RM, Voogd AC. Predictors for extensive nodal involvement in breast cancer patients with axillary lymph node metastases. Breast. 2016; 27: 175-181. [DOI: 10.1016/j.breast.2016.02.006].

10. Mamtani A, Patil S, Van Zee KJ, Cody HS 3rd, Pilewskie M, Barrio AV, Heerdt AS, Morrow M. Age and Receptor Status Do Not Indicate the Need for Axillary Dissection in Patients with Sentinel Lymph Node Metastases. Ann Surg Oncol. 2016 Oct;23 [11]: 3481-3486. [DOI: 10.1245/s10434-016-5259-3].

11. Rabaglio M, Castiglione M. Breast Cancer in Younger Women. In Management of Breast Diseases. Springer, Cham. 2016; [pp. 529-564].

12. Li L, Chen $\mathbf{L Z}$. Factors influencing axillary lymph node metastasis in invasive breast cancer. Asian Pac J Cancer Prev. 2012;13[1]:251-254. [DOI:10.7314/ apjcp. 2012. 13.1.251].

13. Chisthi M M, Kuttanchettiyar KG. Clinicopatho-logical profile of axillary lymph node status in early breast carcinoma-a tertiary care centre experience. Inter Surg J. 2016;3[2]:776-780.

14. Chakraborty A, Bose CK, Basak J, Sen AN, Mishra R, Mukhopadhyay A. Determinants of lymph node status in women with breast cancer: A hospital-based study from eastern India. Indian J Med Res. 2016;143: S45-S51. [DOI:10.4103/ 0971-5916. 191761]

15. Bhardwaj P, Au CC, Benito-Martin A, Ladumor H, Oshchepkova S, Moges R, Brown KA. Estrogens and breast cancer: Mechanisms involved in obesity-related development, growth and progression. J Steroid Biochem Mol Biol. 2019 May; 189:161-170. [DOI: 10.1016/j.jsbmb. 2019. 03.002].

16. Picon-Ruiz M, Morata-Tarifa C, Valle-Goffin JJ, Friedman ER, Slingerland JM. Obesity and adverse breast cancer risk and outcome: Mechanistic insights and strategies for intervention. CA Cancer J Clin. 2017; 67[5]:378-397. [DOI:10.3322/caac.21405].

17. Guldberg TL, Christensen S, Zachariae R, Jensen $A B$. Prognostic factors in early breast cancer associated with body mass index, physical functioning, physical activity \& comorbidity: data from a nationwide Danish cohort. Breast Cancer Res Treat. 2017; 162[1]: 159-167. [doi:10.1007/ s10549-016-4099-y].

18. Keskin O, Aksoy S, Babacan T, Sarici F, Kertmen N, Solak $\mathbf{M}$, et al. Impact of the obesity on lymph node status in operable breast cancer patients. J BUON. 2013;18[4]:824-30. [PMID: 24344004]. 
19. Siotos C, McColl M, Psoter K, Gilmore RC, Sebai ME, Broderick KP, et al. Tumor Site and Breast Cancer Prognosis. Clin Breast Cancer. 2018; 18 [5]: e1045-e1052. [DOI: 10.1016/j.clbc.2018. 05.007].

20. Guo Q, Burgess S, Turman C, Bolla MK, Wang Q, Lush M, et al. Body mass index and breast cancer survival: a Mendelian analysis. Int J Epidemiol. 2017;46 [6]:1814-1822. [DOI:10.1093/ije/ dyx131].

21. Desai AA, Hoskin TL, Day CN, Habermann EB, Boughey JC. Effect of Primary Breast Tumor Location on Axillary Nodal Positivity. Ann Surg Oncol. 2018; 25 [10]:3011-3018. [DOI:10.1245/ s10434-018-6590-7].

22. Ojha SS, Jain RA, Nilkanthe RG, Meenai FG, Abhishek S, Amit HK. Distance of tumor to skin as a predictive marker for axillary lymph node metastasis in cases of breast carcinoma-A retrospective study. Indian J Med Paediat Oncol. 2018;39[3]: 321-325. [DOI: 10.4103/ijmpo. ijmpo_26_17].

23. Kurnaz E, Celebi B, Karapolat B, Eken H, Kucuktulu U. Risk factors for axillary lymph node metastasis in breast cancer. Annals Med Res. 2019; 26 [10]: 213942. [DOI: 10.5455/annalsmedres. 2019. 06.345].

24. Goodman ML, Trinca GM, Walter KR, Papachristou EK, D'Santos CS, Li T, et al. Progesterone receptor attenuates STAT1-Mediated IFN signaling in breast cancer. J Immunol. 2019; 202 [10]: 3076-3086. [DOI:10.4049/jimmunol. 1801152].

25. Sohn HJ, Kim HS, Park SJ, Shin HC. Reliability of Core Needle Biopsy in Evaluating Estrogen Receptor, Progesterone Receptor, and Human Epidermal Growth Factor Receptor 2, and Ki-67 Status. J Breast Dis. 2016;4 [2]:70-76. [10.14449/ jbd.2016.4.2.70]

26. Tong ZJ, Shi NY, Zhang ZJ, Yuan XD, Hong XM. Expression and prognostic value of HER-2/neu in primary breast cancer with sentinel lymph node metastasis. Biosci Rep. 2017; 37[ 4]: BSR20170121. [DOI: 10.1042/BSR20170121].

27. Badowska-Kozakiewicz AM, Sobol M, Patera J, Kozłowski W. Immunohistochemical evaluation of human epidermal growth factor receptor 2 and estrogen and progesterone receptors in invasive breast cancer in women. Arch Med Sci. 2013; 9 [3]: 466-471. [DOI: 10. 5114/aoms.2012.31010].

28. Öz B, Akcan A, Doğan S, bdulrezzak Ü, Aslan D, Sözüer $E$, et al. Prediction of nonsentinel lymph node metastasis in breast cancer patients with one or two positive sentinel lymph nodes. Asian J Surg. 2018; 41[1]:12-19. [DOI: 10.1016/j.asjsur. 2016. 06.001].
29. Ilhem B, Sabrine B, Aïda G, Iness Z, Aida G, Olfa J, et al. Breast cancer in elderly women: role of tumor characteristics in predicting axillary lymph node metastasis. Pan Arab J Oncol. 2019;12[2]. [DOI: 10.1016/j.ejso. 2019. 11.058]

30. Fujii T, Yanagita Y, Fujisawa T, Hirakata T, lijima M, Kuwano H. Implication of extracapsular invasion of sentinel lymph nodes in breast cancer: prediction of nonsentinel lymph node metastasis. World J Surg. 2010; 34[3]: 544-548. [DOI:10.1007/s00268-0090389-4].

31. Zengel B, Yararbas U, Duran A, Uslu A, Elıyatkın N, Demırkıran MA, et al. Comparison of the clinicpathological features of invasive ductal, invasive lobular, and mixed [invasive ductal plus invasive lobular] carcinoma of the breast. Breast Cancer. 2015; 22[4]:374-381. [DOI:10.1007/s12282-013-0489-8].

32. Chen Z, Yang J, Li S, Lv M, Shen Y, Wang B, et al. Invasive lobular carcinoma of the breast: A special histological type compared with invasive ductal carcinoma. PLoS One. 2017;12[9]:e0182397. [DOI: 10.1371/journal.pone.0182397].

33. Williams LA, Hoadley KA, Nichols HB, Geradts J, Perou CM, Love MI, Olshan AF, Troester MA. Differences in race, molecular and tumor characteristics among women diagnosed with invasive ductal and lobular breast carcinomas. Cancer Causes Control. 2019; 30[1]:31-39. [DOI: 10.1007/s10552018-1121-1].

34. Bertoni N, de Souza MC, Crocamo S, Szklo M, de Almeida LM. Is a Family History of the Breast Cancer Related to Women's Cancer Prevention Behaviors? Int J Behav Med. 2019; 26[1]:85-90. [DOI: 10.1007/ s12529-018-9737-9].

35. Brewer HR, Jones ME, Schoemaker MJ, Ashworth A, Swerdlow AJ. Family history and risk of breast cancer: an analysis accounting for family structure. Breast Cancer Res Treat. 2017; 165[1]: 193200. [DOI:10.1007/s10549-017-4325-2]. 